\title{
The Effects of Advance Care Planning on Decision Conflict and Psychological Distress: A Systematic Review and Meta-Analysis of Randomized Controlled Trials
}

\author{
Young-Ran Yeun, Ph.D. \\ Department of Nursing, Kangwon National University, Samcheok, Korea
}

\begin{abstract}
Purpose: Advance care planning (ACP) is widely understood to improve end-of-life care. This systematic review and meta-analysis aimed to examine the effects of ACP interventions on decision conflict and psychological distress. Methods: A search of PubMed, CINAHL, CENTRAL, EMBASE, KISS, KoreaMed, and RISS was conducted in November 2020. The study included randomized controlled trials. Data were pooled using fixed- and randomeffects models. Results: Fourteen studies were identified that cumulatively included 1,548 participants. ACP interventions were effective in alleviating decision conflict $(\mathrm{d}=-0.53 ; 95 \%$ CI: -0.83 to -0.23 ), depression ( $d=-1.22 ; 95 \%$ CI: -1.71 to -0.74 ) and anxiety ( $d=-0.76$; $95 \%$ CI: -1.12 to -0.39 ). Conclusion: ACP interventions have significant positive effects on reducing decision conflict and psychological distress. A high level of bias was shown related to allocation concealment and blinding. The results of this study are expected to be useful for end-of-life care providers to improve the effectiveness of ACP interventions.
\end{abstract}

Key Words: Advance care planning, Psychological conflict, Psychological distress, Hospice care
Received February 24, 2021

Revised June 23, 2021

Accepted June 24, 2021

\section{INTRODUCTION}

The Act on Hospice and Palliative Care and Decisions on Life-Sustaining Treatment for Patients at the End of Life has been in place since 2018 in South Korea to protect human dignity and values, and advance directives and physician orders for life-sustaining treatment (POLST) are now actively in use. According to the National Agency for the Management of Life-Sustaining Treatment, however, only $33.4 \%$ of total deaths involved written advance directives or POLST, and 96.5\% of advance directives or POLST were not made by patients themselves, but rather by patients' families using statements and agreements [1].
Patients with malignant or chronic diseases face a variety of issues as they near the end of their lives. Aside from medical problems, patients may face family-related tensions and conflicts between medical personnel and family members that can result in medical disputes [2]. Advance care planning (ACP) is a communicative process through which patients' preferences for end-of-life care and medical treatment are outlined if patients are expected to be unable to make such decisions on their own in the future [3]. This usually entails discussing the disease's prognosis and various treatment options, preparing an advance directive, and appointing a surrogate to make medical decisions [4]. Decision conflict is a state of confusion over which choices to make to minimize risk or avoid failure 
according to an individual's personal values during the decision-making process [5]. A high degree of decision conflict can have a negative impact on quality of life and cause anxiety, stress, and regret [6]. From a health service perspective, medical disputes can increase the possibility of patients missing their optimal treatment windows [7]. Thus, to improve the quality of end-of-life care and related medical services, it is important to concentrate on decision conflict. If ACP is undertaken ahead of time, the patient is more likely to receive care according to his or her wishes at the end of life, and communication between family and medical personnel is likely to improve, leading to less conflict and distress [8,9]. Psychological distress refers to a state of emotional or mental suffering due to demands or stressors that are difficult to cope with in daily life, and it manifests as depression, anxiety, and hopelessness [10]. Depression and anxiety tend to worsen the general condition of patients related to treatment, decrease satisfaction with health services, and cause decision conflict [11]. As a result, depression and anxiety should be regularly assessed and managed. Carrying out ACP has been found to increase knowledge of end-of-life care without reducing hope, increasing despair, or inducing anxiety in patients with advanced cancer $[12,13]$.

The impact of ACP interventions has been much debated over the last few years. However, few reviews have examined the effects of ACP on decision conflict and psychological distress. Most systematic reviews of ACP have studied the implementation of ACP interventions, the execution of advance directives, end-of-life treatment instructions such as do-notresuscitate (DNR) orders, and communication-related variables [14-18]. The aim of this review and meta-analysis was to collect evidence related to the effects of ACP interventions on decision conflict and psychological distress.

\section{METHODS}

\section{Study design}

This study is a systematic literature review and meta-analysis that aimed to investigate the effects of ACP interventions on decision conflict and psychological distress.

\section{Eligibility criteria}

The participants, intervention, comparisons, outcomes, setting, and study design (PICO-SD), which were the key considerations for the literature selection, were as follows. The participants $(\mathrm{P})$ were patients with malignant or chronic diseases. The intervention (I) was any ACP intervention that included end-of-life discussions about a living will, durable power of attorney, or DNR or do-not-hospitalize (DNH) orders. End-of-life discussions are conversations among professionals, patients, and relatives concerning a patient's wishes and decisions related to the end of life. Durable power of attorney ensures that, in the event of a medical emergency or mental dysfunction, another person will execute the patient's health plans on his or her behalf. Comparisons (C) were made between participants who received an ACP intervention and those who did not receive an ACP intervention or received only a placebo intervention. The outcomes $(\mathrm{O})$ were decision conflict, depression, and anxiety. Depression and anxiety were assessed to measure psychological distress. The settings (S) were hospitals, nursing homes, outpatient clinics, and communities. The study design (D) was randomized controlled trials (RCTs). The exclusion criteria for the studies in this review were the presence of children as participants; outcome variables other than decision conflict, depression, or anxiety; a non-RCT study design; and an inability to obtain the mean and standard deviation of the measured results.

\section{Literature search}

The data were selected from papers published from the databases' inception and extending to November 2020. The electronic databases used for the literature search were PubMed, CINAHL, CENTRAL, EMBASE, KISS, KoreaMed, and RISS. $\mathrm{MeSH}$ terms, the text of titles, and abstracts were applied when relevant in the search formula. The search terms were as follows: (advance care plan* OR advance care direct* OR advance health care plan* OR advance medical direct* OR advance medical plan* OR future care plan*) AND (end of life OR living will* OR power of attorney OR DNH OR DNR) AND (hospice OR life prolonging OR life support OR life sustaining OR palliative OR advanced OR severely OR serious OR malignant OR chronic) AND (decision making 
OR decision* conflict OR distress OR depression OR anxiety) AND (intervention OR therapy OR programme OR program OR trial OR randomized OR controlled).

\section{Data extraction}

In the first stage of data selection, an electronic database was searched in order to identify relevant papers. In the second stage, duplicate data were excluded by checking the author names, publication years, titles, and journal names of the collected papers. In the third stage, related data were selected by applying the inclusion and exclusion criteria to the titles and abstracts of the collected papers. In the fourth and last stage, the final data were selected after reviewing the full texts of the papers. Information on the selected trials was maintained in a coding table in which the author, year of publication, country of publication, number of participants, age and gender ratios of the participants, type of intervention, setting, intervention provider, status of involvement of family members or surrogates, comparative intervention, outcome variables, measurement tools, and mean and standard deviation were recorded for each paper.

\section{Methodological quality}

The methodological quality of the trials was evaluated using the risk of bias (RoB) tool, which reviews bias for six items: random sequence generation, allocation concealment, blinding of participants and personnel, blinding of outcome assessment, incomplete outcome data, and selective reporting [19]. For each source, the RoB was judged as low, unclear, or high.

\section{Ethical consideration}

This study was exempted from review by the institutional review board (IRB No. KNU 2021-02-012).

\section{Data analysis}

The effect size and homogeneity of ACP interventions were analyzed using the Review Manager Version 5.3 program (RevMan, The Cochrane Collaboration, Oxford, UK). When homogeneity was confirmed, the effect size was calculated using a fixed-effect model, and when heterogeneity was confirmed, the effect size was calculated using a random-effect model. The statistical significance of the effect size was deter- mined based on the overall effect test, a confidence interval (CI) of $95 \%$, and a significance level of $5 \%$. The homogeneity of studies was tested using the Higgins $\mathrm{I}^{2}$ statistic, and publication bias was tested using a funnel plot.

\section{RESULTS}

\section{Literature search}

In the first stage of data selection, 1,297 articles from the databases were screened. In the second stage, duplicate articles were excluded, after which 563 articles remained. In the third stage, 149 papers were selected based on the inclusion and exclusion criteria, focusing on the titles and abstracts of papers. In the fourth stage, the full texts of the remaining studies were reviewed, and 14 studies were finally selected (Figure 1).

\section{Study characteristics}

Ten $(71.4 \%)$ of the 14 studies were conducted in the USA and four $(28.6 \%)$ in other countries.

Eleven trials were performed in a hospital setting and three in a community setting. There were 1,548 participants in total, 798 of whom were in an experimental group and 750 of whom were in a control group. The median sample size was 98 participants, with a range of 18 to 230 participants. Six papers $(42.9 \%)$ examined interventions that were conducted by nurses who received professional ACP training, and nine trials (64.3\%) included family members or surrogates in the inter-

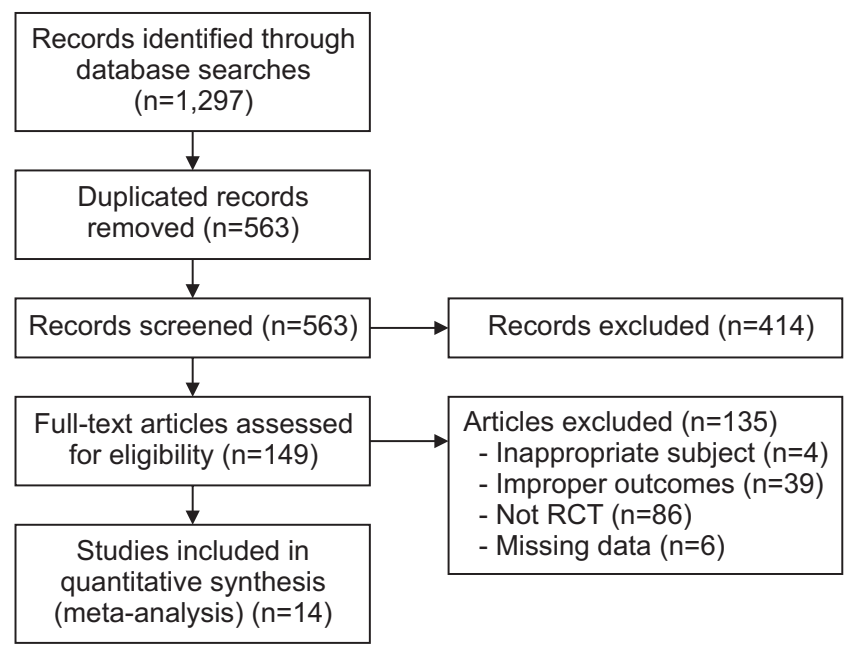

Figure 1. Flow diagram of the study selection process. 


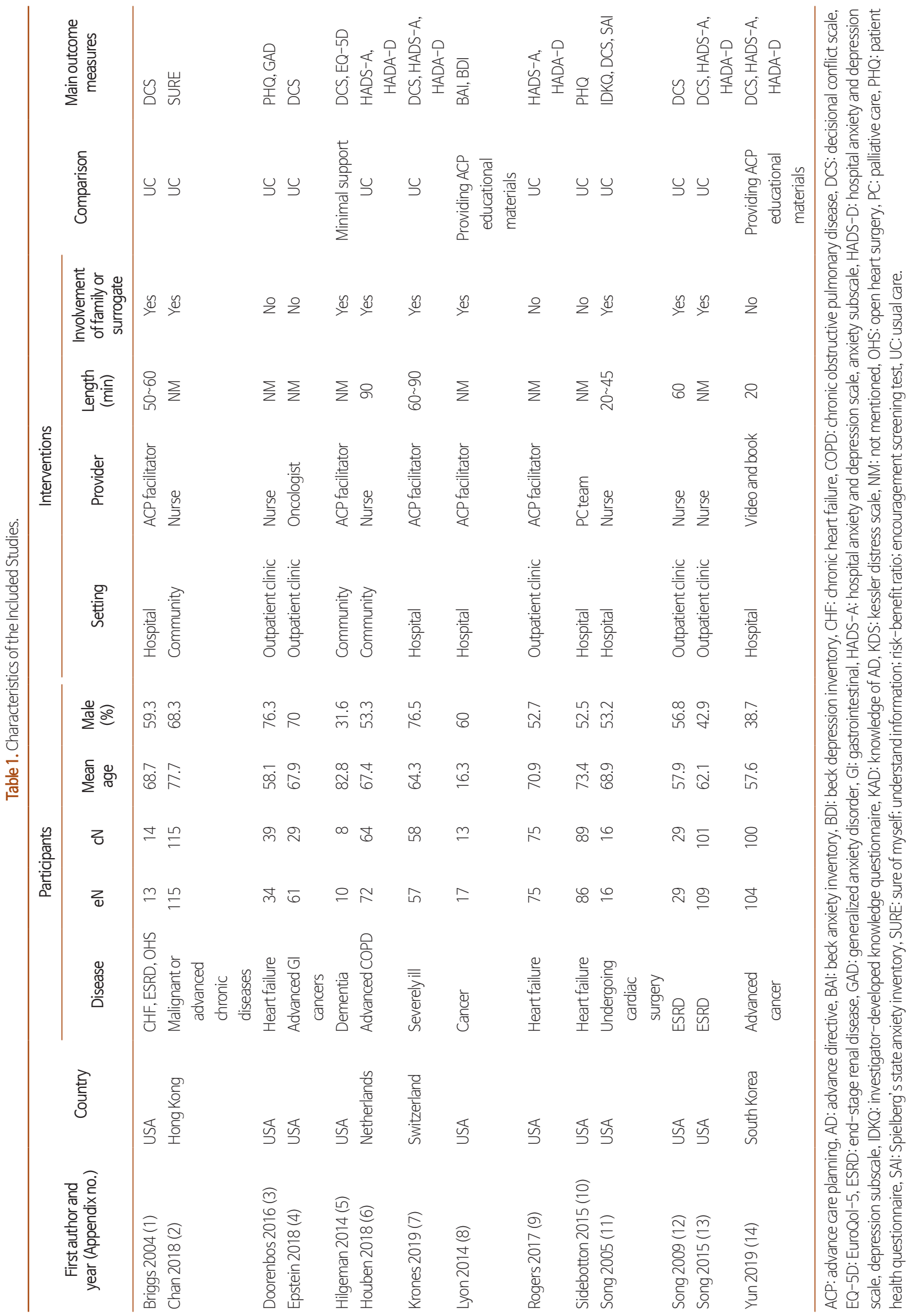




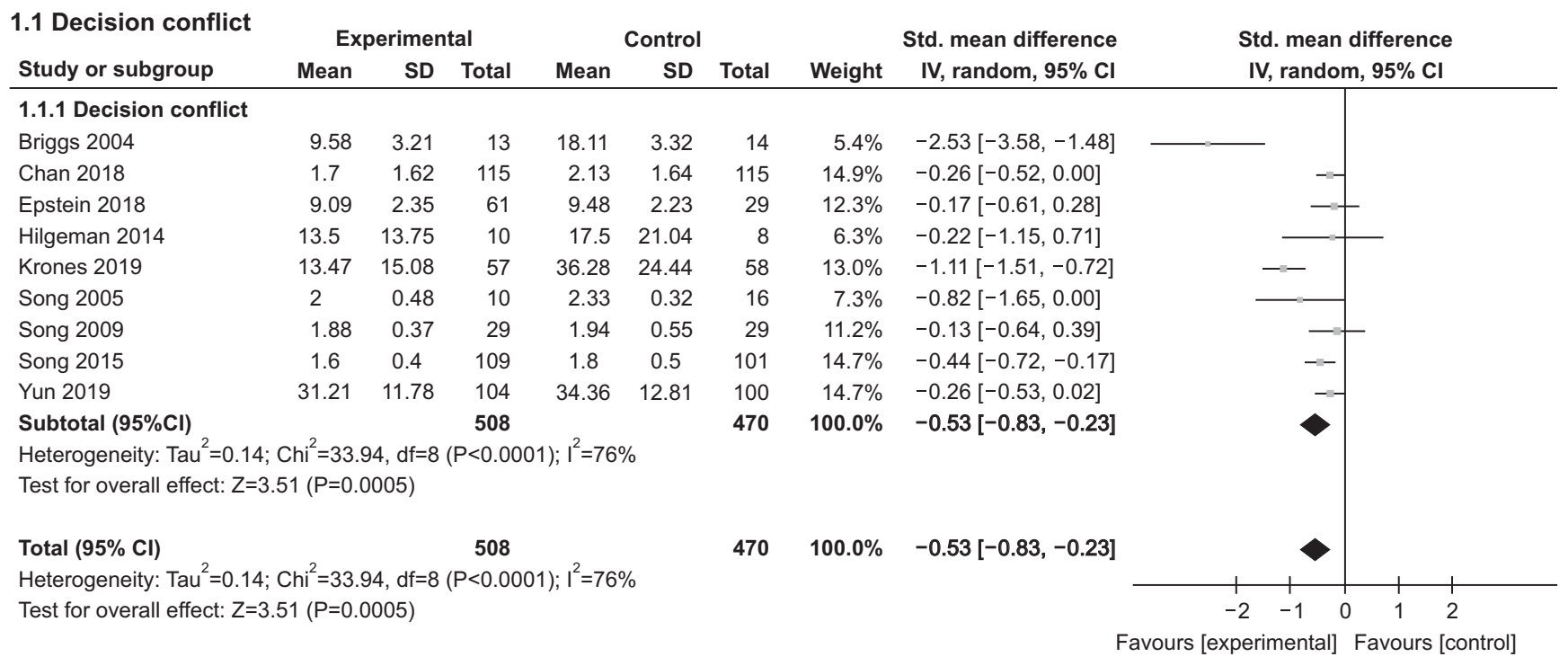

\subsection{Depression}

Study or subgroup

\section{Experimental}

1.2.1 Depression

Doorenbos 2016

Houben 2018

Krones 2019

Lyon 2014

Rogers 2017

Sidebotton 2015

Song 2015

Yun 2019

Subtotal $(95 \% \mathrm{Cl})$

Heterogeneity: $\mathrm{Chi}^{2}=22.23, \mathrm{df}=7(\mathrm{P}=0.002) ; \mathrm{I}^{2}=69 \%$

Test for overall effect: $Z=4.94(P<0.00001)$

Total $(95 \% \mathrm{Cl})$

Heterogeneity: $\mathrm{Chi}^{2}=22.23, \mathrm{df}=7(\mathrm{P}=0.002) ; \mathrm{I}^{2}=69 \%$

Test for overall effect: $Z=4.94(P<0.00001)$

\subsection{Anxiety}

Study or subgroup

\subsubsection{Anxiety}

Doorenbos 2016

Hilgeman 2014

Houben 2018

Krones 2019

Lyon 2014

Rogers 2017

Song 2015

Song 2015

Yun 2019

Subtotal $(95 \% \mathrm{Cl})$

Heterogeneity: Chi $^{2}=19.03, \mathrm{df}=8(\mathrm{P}=0.01) ; I^{2}=58 \%$

Test for overall effect: $Z=4.05(P<0.0001)$

Total $(95 \% \mathrm{Cl})$

Heterogeneity: Chi $^{2}=19.03, \mathrm{df}=8(\mathrm{P}=0.01) \cdot \mathrm{I}^{2}=58 \%$

Test for overall effect: $Z=4.05(P<0.0001)$

\begin{tabular}{|c|c|c|c|c|}
\hline \multicolumn{3}{|c|}{ Control } & \multirow[b]{2}{*}{ Weight } & \multirow{2}{*}{$\begin{array}{l}\text { Mean difference } \\
\text { IV, fixed, } 95 \% \mathrm{CI}\end{array}$} \\
\hline Mean & SD & Total & & \\
\hline 5.6 & 5.8 & 39 & $3.8 \%$ & $-0.13[-2.61,2.35]$ \\
\hline 6.3 & 3.9 & 64 & $11.2 \%$ & $0.10[-1.35,1.55]$ \\
\hline 5.04 & 3.67 & 58 & $11.1 \%$ & $0.69[-0.76,2.14]$ \\
\hline 7.4 & 4.3 & 13 & $2.0 \%$ & $-1.10[-4.54,2.34]$ \\
\hline 6.4 & 4.3 & 75 & $14.5 \%$ & $-1.80[-3.07,-0.53]$ \\
\hline 31.14 & 14 & 89 & $1.2 \%$ & $-1.43[-5.81,2.95]$ \\
\hline 5.9 & 3.2 & 101 & $35.2 \%$ & $-2.50[-3.32,-1.68]$ \\
\hline \multirow[t]{2}{*}{7.3} & 3.57 & 100 & $20.9 \%$ & $-0.59[-1.65,0.47]$ \\
\hline & & 539 & $100.0 \%$ & $-1.22[-1.71,-0.74]$ \\
\hline
\end{tabular}

Favours [experimental] Favours [control]

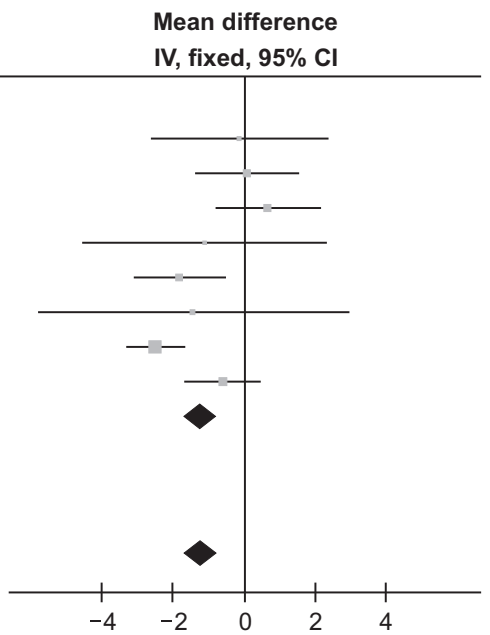

Favours [experimental] Favours [control]

$539 \quad 100.0 \% \quad-1.22[-1.71,-0.74]$

Mean SD Total Mean SD Total Weight IV, fixed, $95 \% \mathrm{Cl}$

Mean difference

IV, fixed, $95 \% \mathrm{CI}$

Figure 2. Forest plot of the effect size of advance care planning interventions on decision conflict, depression, and anxiety. 
vention (Table 1, Appendix 1).

\section{ACP effects}

Nine studies examined the effects of ACP interventions on decision conflict. The effect size was medium $(-0.53$ [95\% CI: -0.83 to -0.23$])$, and the heterogeneity was high $\left(\mathrm{I}^{2}=76 \%\right)$. Eight trials investigated the effects of ACP on depression, and a large effect size was found ( -1.22 [95\% CI: -1.71 to -0.74$]$ ) with moderate heterogeneity $\left(\mathrm{I}^{2}=69 \%\right)$. Nine papers examined the relationship between ACP and anxiety, with an effect size of $-0.76(95 \%$ CI: -1.12 to -0.39$)$ and moderate heterogeneity $\left(\mathrm{I}^{2}=58 \%\right)$ (Figure 2$)$.

The following moderators were used to perform subgroup analysis for all pooled effect sizes: setting, provider, and family or surrogate involvement. ACP interventions were more effective in hospital or clinic settings than in community settings. Implementation by nurses was the most effective, and interventions that included family members or surrogates were more effective than those that were conducted with the patient alone (Table 2). Publication bias was not detected for any of the variables.

\section{Methodological quality}

Seven trials $(50.0 \%)$ reported adequate methods of random sequence generation, and 13 papers (92.9\%) explained the reasons for incomplete outcome data. Allocation concealment was performed in only one trial (7.1\%). Blinding of participants was not possible in nine trials due to the nature of the interventions, thus resulting in a high risk of performance bias. Selective reporting was adequately addressed in all studies (Figure 3).

\section{DISCUSSION}

Previously, there was no firm evidence on the effects of ACP interventions on decision conflict and psychological distress. This literature review and meta-analysis examined 14 RCTs that included 1,548 participants and found that ACP interventions were effective for alleviating decision conflict, depression, and anxiety.

This review is the first meta-analysis to examine the effects of ACP interventions on decision conflict and psychological

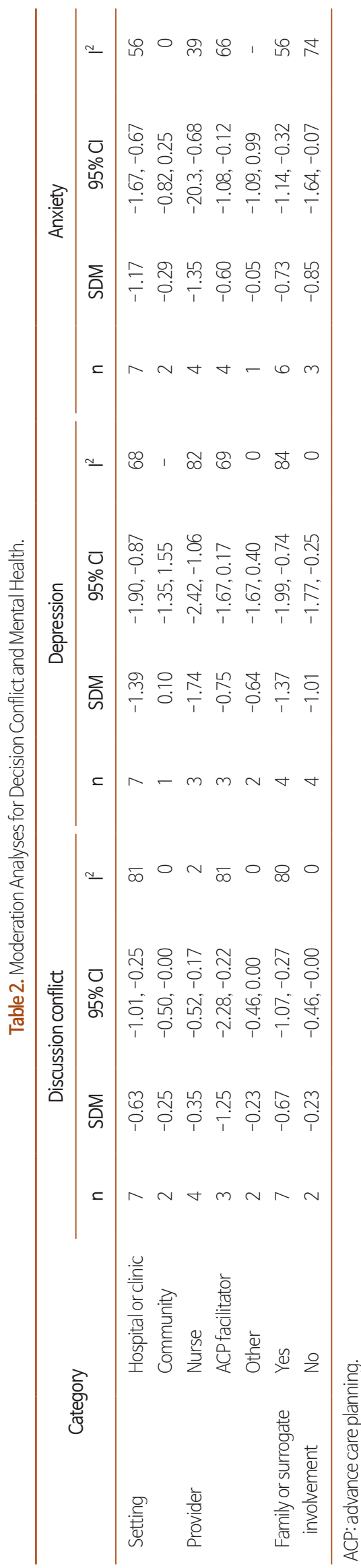

http://www.e-jhpc.org 149 


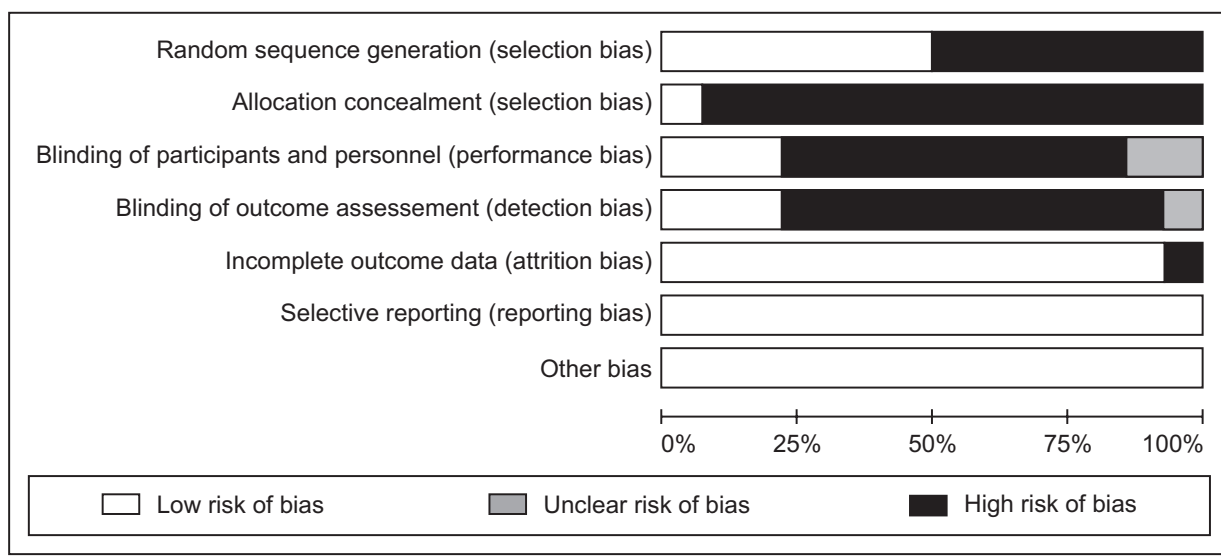

Figure 3. Assessment of methodological quality. distress among patients suffering from a malignant or chronic disease. ACP interventions initially tended to focus on the $\mathrm{ex}^{-}$ ecution of advance directives. However, after evidence was found that advance directives do not significantly enhance end-of-life care [20,21], ACP for patients has evolved to concentrate more on preparing patients for decision-making related to treatment at the end of life while minimizing psychological distress. For example, Song et al. [22] found that participants in an ACP intervention (Sharing Patient's Illness Representations to Increase Trust, SPIRIT) were interested in addressing end-of-life care since, rather than focusing on the execution of advance directives, SPIRIT encouraged patients to consider and discuss the possibility of decision-making about future care, as well as how they would feel about care options at the end of life.

Patients with a malignant or chronic disease suffer from physical side effects such as fatigue and functional regression, as well as emotional discomfort such as feelings of failure due to changes in body image and anxiety about end-of-life care [23]. Many of the studies on ACP interventions included in our analysis identified the concerns and preferences of patients concerning their disease state or end-of-life care through conversation or discussion $[22,24,25]$. Reducing stimulation by examining the reasons why patients experience depression or anxiety and presenting patients with adequate information to address these issues has been found to be successful in reducing psychological distress. This finding aligns with those of a study by Nishikawa et al. [26] that found that an ACP intervention contributed to an increase in discussions about the ACP process between medical personnel and patients, thus reducing depression in patients.

The meta-analysis of decision conflict showed a high degree of heterogeneity, and the meta-analysis of psychological distress showed a moderate degree of heterogeneity. Subgroup analysis was performed to further examine these findings, but heterogeneity remained high in some subgroups. Therefore, further research is needed to understand these meta-analysis results. A subgroup analysis showed that involving family members or surrogates in ACP interventions is more effective than conducting ACP interventions involving the patient alone. The importance of family members or surrogates has been recognized since they are often involved in key care decisions at the end of life $[27,28]$. In a family-centered system such as that of Korea, the opinions of patients are often excluded from the decision-making process or ignored when they run contrary to the family's wishes [29,30]. When patients, families, and medical personnel share opinions through ACP interventions, patients and family members are better able to voice their opinions and reach a consensus. ACP interventions should be able to provide medical professionals with guidelines for starting discussions with patients and their families about end-of-life or life-sustaining care that patients and their families are hesitant to address.

In the methodological quality evaluation of the trials included in this systematic review, $92.9 \%$ of studies did not show allocation concealment. To investigate the pure effects of ACP interventions, efforts to reduce selection bias, such as the use of centrally controlled randomization and sequentially numbered containers, should be made. It was also found that study participants or outcome measurers were blinded in only $35.7 \%$ 
of the studies included in our analysis. Blinding is a method for preventing bias in performance and result confirmation in research. This figure suggests that double-blind experimental studies should be conducted in the future to better evaluate the effectiveness of ACP interventions.

This study is notable since it is the first to examine the impact of ACP interventions on decision conflict, anxiety, and depression and provides evidence for the development and implementation of ACP in the future. The limitations of this study are as follows. First, the long-term effects of ACP interventions could not be analyzed since the meta-analysis was performed using data on the effects of ACP interventions mea- sured immediately after ACP had been completed. Second, exploring the source of variation in the exact effect sizes of ACP interventions was difficult since the full content of many of the trials included in the study was not available. The intensity of the ACP interventions should also be considered in future studies.

\section{CONFLICT OF INTEREST}

No potential conflict of interest relevant to this article was reported.

\section{REFERENCES}

1. Current Status of Life-Sustaining Treatment System [Internet]. Seoul: National Agency for Management of Life-Sustaining Treatment; 2019. [cited 2020 Dec 27]. Available from: https://www.lst.go.kr./comm/monthlyStatistics.do.

2. Kim H, Kim K. Palliative cancer care stress and coping among clinical nurses who experience end-of-life care. J Hosp Palliat Nurs 2020;22:115-22.

3. Rietjens JAC, Sudore RL, Connolly M, van Delden JJ, Drickamer MA, Droger M, et al. Definition and recommendations for advance care planning: an international consensus supported by the European Association for Palliative Care. Lancet Oncol 2017;18:e543-51.

4. Steel AJ, Owen LH. Advance care planning: the who, what, when, where and why. Br J Hosp Med (Lond) 2020;81:1-6.

5. LeBlanc A, Kenny DA, O'Connor AM, Legare F. Decisional conflict in patients and their physicians: a dyadic approach to shared decision making. Med Decis Making 2009;29:61-8.

6. Yamauchi K, Nakao M, Nakashima M. Correlates of regret with treatment decision-making among Japanese women with breast cancer: results of an internet-based cross-sectional survey. BMC Womens Health 2019;19:86.

7. Knops AM, Goossens A, Ubbink DT, Legemate DA, Stalpers L, Bossuyt PM. Interpreting patient decisional conflict scores: behavior and emotions in decisions about treatment. Med Decis Making 2013;33:78-84.

8. Prater LC, Wickizer T, Bower JK, Bose-Brill S. The impact of advance care planning on end-of-life care: Do the type and timing make a difference for patients with advanced cancer referred to hospice? Am J Hosp Palliat Care 2019;36:1089-95.

9. Raskin J, Vermeersch K, Everaerts S, Bleyenbergh PV, Janssens W. Do-not-resuscitate orders as part of advance care planning in patients with COPD. ERJ Open Res 2018;4:00116-2017.

10. Mack JW, Weeks JC, Wright AA, Block SD, Prigerson HG. End-of-life discussions, goal attainment, and distress at the end of life: predictors and outcomes of receipt of care consistent with preferences. J Clin Oncol 2010;28:1203-8.

11. You HM, Park EY. Relationships between attitude towards treatment, distress, and decision conflict among cancer patients receiving chemotherapy. Asian Oncol Nurs 2019;19:242-51.

12. Green MJ, Schubart JR, Whitehead MM, Farace E, Lehman E, Levi BH. Advance care planning does not adversely affect hope or anxiety among patients with advanced cancer. J Pain Symptom Manage 2015;49:1088-96.

13. Lyon ME, Jacobs S, Briggs L, Cheng YI, Wang J. A longitudinal, randomized, controlled trial of advance care planning for teens with cancer: anxiety, depression, quality of life, advance directives, spirituality. J Adolesc Health 2014;54:710-7.

14. Houben CHM, Spruit MA, Groenen MTJ, Wouters EFM, Janssen DJA. Efficacy of advance care planning: a systematic review and metaanalysis. J Am Med Dir Assoc 2014;15:477-89.

15. Jain A, Corriveau S, Quinn K, Gardhouse A, Vegas DB, You JJ. Video decision aids to assist with advance care planning: a systematic review and meta-analysis. BMJ Open 2015;5:e007491.

16. Robinson L, Dickinson C, Rousseau N, Beyer F, Clark A, Hughes J, et al. A systematic review of the effectiveness of advance care planning interventions for people with cognitive impairment and dementia. Age Ageing 2012;41:263-9.

17. White P, Cobb D, Vasilopoulos T, Davies L, Fahy B. End-of-life discussions: Who's doing the talking? J Crit Care 2018;43:70-4.

18. Hong M, Kim K. Advance care planning among ethnic/racial minority older adults: prevalence of and factors associated with informal talks, durable power of attorney for health care, and living will. Ethn Health 2020:1-10. 
19. Higgins JPT, Green S. Cochrane handbook for systematic reviews of interventions. New York: John Wiley \& Sons; 2011.

20. Perkins HS. Controlling death: the false promise of advance directives. Ann Intern Med 2007;147:51-7.

21. McMahan RD, Knight SJ, Fried TR, Sudore RL. Advance care planning beyond advance directives: perspectives from patients and surrogates. J Pain Symptom Manage 2013;46:355-65.

22. Song MK, Ward SE, Fine JP, Hanson LC, Lin FC, Hladik GA, et al. Advance care planning and end-of-life decision making in dialysis: a randomized controlled trial targeting patients and their surrogates. Am J Kidney Dis 2015;66:813-22.

23. Sumalinog R, Harrington K, Dosani N, Hwang SW. Advance care planning, palliative care, and end-of-life care interventions for homeless people: A systematic review. Palliat Med 2017;31:109-19.

24. Yun YH, Kang E, Park S, Koh SJ, Oh HS, Keam B, et al. Efficacy of a decision aid consisting of a video and booklet on advance care planning for advanced cancer patients: randomized controlled trial. J Pain Symptom Manage 2019;58:940-8.

25. Krones T, Budilivschi A, Karzig I, Otto T, Valeri F, Biller-Andorno N, et al. Advance care planning for the severely ill in the hospital: a randomized trial. BMJ Support Palliat Care 2019;bmjspcare-2017-001489.

26. Nishikawa Y, Hiroyama N, Fukahori H, Ota E, Mizuno A, Miyashita M, et al. Advance care planning for adults with heart failure. Cochrane Database Syst Rev 2020;2:CD013022.

27. Chan HY, Ng JS, Chan KS, Ko PS, Leung DY, Chan CW, et al. Effects of a nurse-led post-discharge advance care planning programme for community-dwelling patients nearing the end of life and their family members: A randomised controlled trial. Int I Nurs Stud 2018;87:2633.

28. Hilgeman MM, Allen RS, Snow AL, Durkin DW, DeCoster J, Burgio LD. Preserving Identity and Planning for Advance Care (PIPAC): preliminary outcomes from a patient-centered intervention for individuals with mild dementia. Aging Ment Health 2014;18:411-24.

29. Jang KH, Kang KH, Kim DR, Im HN, Kim KH. A study on the motivation to write signing advance medical directives. JKAIS 2019;20:243-9.

30. Yu HI, Lee YH. Middle-aged adults' attitudes toward dignified death and advance directives, and knowledge of advance directives. J Korean Clin Nurs Res 2020;26:86-96. 
Appendix 1. List of Studies Included in Meta-Analysis.

1. Briggs LA, Kirchhoff KT, Hammes BJ, Song MK, Colvin ER. Patient-centered advance care planning in special patient populations: a pilot study. J Prof Nurs 2004; 20:47-58.

2. Chan HY, Ng JS, Chan KS, Ko PS, Leung DY, Chan CW, et al. Effects of a nurse-led post-discharge advance care planning programme for community-dwelling patients nearing the end of life and their family members: A randomised controlled trial. Int I Nurs Stud 2018;87:2633.

3. Doorenbos AZ, Levy WC, Curtis JR, Dougherty CM. An intervention to enhance goals-of-care communication between heart failure patients and heart failure providers. J Pain Symptom Manage 2016;52:353-60.

4. Epstein AS, O'Reilly EM, Shuk E, Romano D, Li Y, Breitbart W, et al. A randomized trial of acceptability and effects of values-based advance care planning in outpatient oncology: person-centered oncologic care and choices. J Pain Symptom Manage 2018; 56:169-77.

5. Hilgeman MM, Allen RS, Snow AL, Durkin DW, DeCoster J, Burgio LD. Preserving Identity and Planning for Advance Care (PIPAC): preliminary outcomes from a patient-centered intervention for individuals with mild dementia. Aging Ment Health 2014;18:411-24.

6. Houben CHM, Spruit MA, Luyten H, Pennings HJ, van den Boogaart VEM, Creemers JPHM, et al. Cluster-randomised trial of a nurse-led advance care planning session in patients with COPD and their loved ones. Thorax 2019;74:328-36.

7. Krones T, Budilivschi A, Karzig I, Otto T, Valeri F, Biller-Andorno N, et al. Advance care planning for the severely ill in the hospital: a randomized trial. BMJ Support Palliat Care 2019; bmjspcare-2017-001489.

8. Lyon ME, Jacobs S, Briggs L, Cheng YI, Wang J. A longitudinal, randomized, controlled trial of advance care planning for teens with cancer: anxiety, depression, quality of life, advance directives, spirituality. J Adolesc Health 2014;54:710-7.

9. Rogers JG, Patel CB, Mentz RJ, Granger BB, Steinhauser KE, Fiuzat M, et al. Palliative care in heart failure: the PAL-HF randomized, controlled clinical trial. J Am Coll Cardiol 2017;70:331-41.

10. Sidebottom AC, Jorgenson A, Richards H, Kirven J, Sillah A. Inpatient palliative care for patients with acute heart failure: outcomes from a randomized trial. J Palliat Med 2015;18:134-42.

11. Song MK, Kirchhoff KT, Douglas J, Ward S, Hammes B. A randomized, controlled trial to improve advance care planning among patients undergoing cardiac surgery. Med Care 2005;43:1049-53.

12. Song MK, Ward SE, Happ MB, Piraino B, Donovan HS, Shields AM, et al. Randomized controlled trial of SPIRIT: an effective approach to preparing African-American dialysis patients and families for end of life. Res Nurs Health 2009;32:260-73.

13. Song MK, Ward SE, Fine JP, Hanson LC, Lin FC, Hladik GA, et al. Advance care planning and end-of-life decision making in dialysis: a randomized controlled trial targeting patients and their surrogates. Am J Kidney Dis 2015;66:813-22.

14. Yun YH, Kang E, Park S, Koh SJ, Oh HS, Keam B, et al. Efficacy of a decision aid consisting of a video and booklet on advance care planning for advanced cancerpPatients: randomized controlled trial. J Pain Symptom Manage 2019;58:940-8. 